\title{
2 Are Hard Cases Vague Cases?
}

\author{
Ruth Chang ${ }^{1}$
}

In a hard case of comparison between two items, it seems that neither is better or worse than the other and yet nor are they equally good. If you are comparing careers in investment banking and interior design, you might judge that the banking career is better in some relevant respects, the design career better in other relevant respects, and yet neither is at least as good as the other overall. Or if you are comparing the evidence for believing that there is a God and the evidence for disbelieving (or withholding judgment), you might judge that the case for belief is better in some respects, worse in others, and yet the evidence for each attitude is not at least as warrant-providing or justifying as the other. As these cases illustrate, hard cases occur in both the practical and theoretical domains. In their simplest form, they are normative comparisons of items, $\mathrm{A}$ and $\mathrm{B}$, with respect to a "covering consideration," "V," such as "goodness as a career" or "epistemic warrant," in which it seems that none of the usual trichotomy of relations, "better than," "worse than," and "equal to," hold.

How should we understand such cases? There are four familiar "i" explanations: hard cases are hard (i) because we are ignorant of relevant normative or nonnormative facts; (ii) because the items are incommensurable - i.e., their normative merits are not cardinally measurable; (iii) because the items are incomparable; or (iv) because the relevant concepts or facts are indeterminate or vague. I have previously argued that these four explanations, whether taken jointly or severally, are inadequate explanations of hard cases, that is, when taken together or considered individually, they fail as an adequate explanation of all hard cases (Chang 1997, 2002a, 2012, 2017, forthcoming).

Although I have argued against indeterminacy as an explanation of hard cases, my arguments have been less directed since it has always seemed to me that indeterminacy is the least plausible way of explaining hard cases. In holding this view, however, I am in disagreement with a large number of philosophers (Griffin (1986); Broome (1997, this volume); Wasserman (2004); Qizilbash (2005, 2007, 2014); Sugden (2009); Klocksiem (2010); Constantinescu (2012, 2016); Elson (2014), Andersson (2015); Williams

DOI: $10.4324 / 9781003148012-4$ 
(2014, 2016); Dougherty (2016); and Thomas (forthcoming)). Indeed, most of those writing in the area suggest that the right way to think about hard cases is in terms of indeterminacy, and in terms of vagueness in particular. ${ }^{2}$

In this chapter, I provide further explanation of why I think understanding hard cases in terms of vagueness is a mistake. Vagueness both under-delivers in that it fails to explain a critical feature of hard cases and over-delivers in that it imposes a feature that hard cases do not - and should not - have. I then offer my own Goldilocks explanation of hard cases, with specific attention to how it solves the two difficulties that plague vagueness accounts. I end by offering a nudge to proponents of vagueness; given their insights about hard cases, the distance they need to travel to accept my explanation of hard cases - and thereby avoid the two problems with their account - is not as great as they may think.

Two points of clarification. First, my focus will be on a subclass of hard cases, what we might call paradigmatic hard cases - those in which the items being compared are qualitatively different with respect to the covering consideration, and it seems that neither is better than the other or that they are equally good: qualitatively different careers, say, one in investment banking and the other in interior design with respect to goodness as a career; qualitatively different paintings, say, an abstract impressionist painting vs. a photograph with respect to aesthetic merit; qualitatively different types of theory, say, evolutionary theory vs. quantum mechanics with respect to explanatory power; qualitatively different types of evidence, say, statistical vs. forensic with respect to epistemic warrant - where neither seems at least as good. Hard cases involving qualitatively different items are rife in human life, are the most difficult to explain, and, I believe, hold the greatest philosophical interest. ${ }^{3}$ Going forward, by "hard cases" I mean cases of this paradigmatic variety.

Second, I take "better than," "worse than", and "equally good" as master normative relations that can, when relativized to an appropriate covering consideration, underlie certain other normative relations, such as being normatively stronger than, normatively less significant than, and equally warrant-providing. So being a stronger normative reason can be expressed as being better with respect to normative strength and having more epistemic warrant can be expressed as being better with respect to epistemic warrant. Sometimes "better than" is understood as confined to comparisons within axiology, but master relations, like "better than," "worse than," "equally good," are not so confined; when we say that two things are "equally good" with respect to V-ness, we are saying that they are normatively speaking equally $\mathrm{V}$, where $\mathrm{V}$-ness may be a nonaxiological consideration. Stipulating that there are such relations in terms of which all comparative relations can be expressed allows us to investigate the structure of normativity as a whole, without restriction as to relata or covering consideration. 


\section{Ruth Chang}

\section{The Problem of Resolutional Remainder}

"A is better than $\mathrm{B}$ with respect to $\mathrm{V}$ " is linguistically vague if there is vagueness somewhere in the predicate "better than with respect to V" or in the concept it expresses (or strictly in "A" or "B" or their associated concepts, but I put that possibility aside here) such that it is indeterminate how the predicate or concept applies to A and B. In hard cases of comparison, we might say that the indeterminacy is in which of the master predicates, "better than," "worse than," and "equally good," when relativized to V, applies to A and B. ${ }^{4}$ Just as it is "hard" to say whether Jason Statham is bald, it is "hard" to say whether investment banking is a better career than interior design. The hardness in hard cases, so the suggestion goes, is a matter of vagueness in our language.

Linguistic vagueness, however, is prima facie pretty implausible as an explanation of hard cases. The hardness in comparing a career in investment banking and one in interior design is substantive and normative, not something that disappears through linguistic stipulation. When it comes to vagueness in language, the difficulty is whether to apply "bald" to Jason Statham or "red" to a colored patch, a problem about whether to call Statham bald or the patch red, a linguistic matter that can be settled through linguistic stipulation. Hard cases are not a matter of whether to call one career better than another but of figuring out the substantive normative matter of how the careers normatively relate (Chang 2002a; Schoenfield 2015). That hard cases are not made easy through linguistic stipulation seems a compelling reason to reject linguistic vagueness as an explanation of such cases. But language and substantive reality may be closer than this quick argument supposes. And there is always the possibility, though highly controversial (e.g., Sainsbury 2010), that the vagueness is metaphysical - that is, in the world rather than in our language, which raises problems that do not necessarily disappear with linguistic stipulation. The arguments I propose against vagueness accounts apply to vagueness in both their linguistic and metaphysical varieties.

Metaphysical vagueness is vagueness not in language but in the world. A relation or property might be thought to hold indeterminately of some items; does the property of being part of a particular cloud hold of a particular water droplet in the sky? It may be thought to be metaphysically indeterminate whether it does. Following Akiba (2004), Barnes (2010), and Williams (2008), we might think that metaphysical vagueness holds when there are multiple fully determinate worlds - some in which, say, a given water droplet is part of the cloud and some in which it is not - but it is indeterminate which of those worlds is the actual world. In hard cases of comparison, we might say that it is metaphysically indeterminate whether $\mathrm{A}$ is better than $\mathrm{B}$ with respect to $\mathrm{V}$ if in some worlds $\mathrm{A}$ is better than $\mathrm{B}$ and in other worlds it is not, and it is indeterminate which world is actual. Just as whether a given water droplet is part of a cloud 
is "hard," so too is whether investment banking is a better career than interior design. The hardness of hard cases, so the suggestion goes, is a matter of vagueness in properties or relations in the world.

Now there is an intuitive sense in which it is appropriate to resolve vagueness through stipulation. If it is vague whether Jason Statham is bald, there is an intuitive sense in which we can "resolve" the question of whether he is simply by arbitrarily stipulating that he is (or isn't). We might say that even though there is an answer to the question of whether he is bald - namely, that it is indeterminate whether he is, the question nevertheless admits of a resolution as to whether he is, and we can always resolve the question by arbitrary stipulation.

By "resolution," I mean the thin, neutral idea of knowable application or lack of application of the predicate, where the identity of the predicate remains the same although the associated concept or property may change through resolution. My interest is in intrinsic resolution - that is, a settling of whether the predicate applies or not solely on the basis of facts about how the items relate, and not on extrinsic factors, such as a million-dollar reward you will get if you resolve the vagueness one way rather than another. ${ }^{5}$

Consider a supervaluational account of semantic vagueness (Fine 1975). Here the problem is in our language; we have a word, "bald," and it is indeterminate whether "bald" applies to Statham. The word "bald" and the concept of baldness it expresses are not sufficiently precise determinately to answer the question of whether Statham is bald. So we can sharpen up the concept of being bald by offering different neighboring concepts of being bald, each of which is represented by a different sharpening, and arbitrarily stipulate that one of those concepts is expressed by the predicate "is bald." There is nothing in our language or concepts that favor choosing one sharpening over another; we can arbitrarily stipulate a predicate and its associated concept as applying to Statham or not.

The same holds for metaphysical vagueness. Here the problem is with the world; there are multiple fully determinate worlds and indeterminacy in which of those worlds is actual. So we can sharpen up the target actual world by choosing one of the fully determinate worlds as actual. There is nothing in the world that favors choosing one determinate world over another; we can arbitrarily stipulate a determinate world in which Statham is bald (or not) as the actual world. As R. J. Williams, one of the leading proponents of metaphysical vagueness, puts it, the resolution of metaphysical vagueness is a matter of "randomly and groundlessly" making a judgment call (R. J. Williams 2016: 429).

Hard cases are different. In a hard case, arbitrary fiat never intrinsically resolves the case. If, in attempting to resolve the hard comparison between investment banking and interior design, you arbitrarily stipulate that the investment career is better, you have not settled the matter but are left with "resolutional remainder" - that is, the substantive question 


\section{Ruth Chang}

of what normative relation holds between the careers has not been closed but remains an open question. Or consider a hard case involving statistical evidence that John committed a tort and individualized evidence that he did not. If you arbitrarily stipulate that the statistical evidence is better with respect to providing epistemic warrant, you do not thereby settle the matter of whether it is - the question of which evidence is weightier remains an open question. In cases of vagueness, by contrast, arbitrary resolution does close the question. Resolutional remainder is a state in the world, not in us, concerning a normative matter. It obtains when that normative matter remains open after an attempt at resolution, however we might think or feel about the case. Vagueness fails to explain why there is resolutional remainder after arbitrary stipulation and thereby under-delivers as an explanation of hard cases (see also Chang 2002a, forthcoming).

It might be thought that "resolutional remainder" in hard cases can be explained away in other terms. When you arbitrarily stipulate which of two careers in a hard choice is better, the matter of what normative relation holds between them remains open perhaps because we can never be sure that we followed the correct epistemic procedure in judging that neither is better, or because we are uneasy about our stipulated resolution since we recognize that our peers may stipulate differently (Williams 2016), or because we are filled with angst, regret or uncertainty in "high stakes" cases, like those involving comparisons of careers (Constantinescu 2012; Williams 2016). These are all extrinsic features of hard cases to which indeterminists have helped themselves in attempting to account for resolutional remainder.

But these suggestions misunderstand resolutional remainder in two ways. First, it is intrinsic to hard cases, not a downstream consequence of arbitrary stipulation that is contingent on the circumstances. Arbitrary stipulation in a hard case leaves resolutional remainder as an intrinsic feature of such cases, regardless of the circumstances surrounding the choice. It is not, for instance, a feature of only "high stakes" cases, like comparisons between careers, places to live, or people to marry. A primary school teacher might face a hard case in judging which of two qualitatively very different finger paintings is more beautiful. If she arbitrarily stipulates that Timmy's is more beautiful than Tommy's, her arbitrary stipulation does not settle the matter; the question of how the paintings relate with respect to beauty remains open, although answering that question may be of little intrinsic or extrinsic importance. Nonarbitrary stipulation in a hard case can be always be made on extrinsic grounds. The fact that Tommy won a prize for a pencil drawing last week may be an extrinsic ground for stipulating this week that Timmy's is more beautiful. Being low stakes, not having adequate time to consider the matter, achieving some benefit, and so on, can be extrinsic grounds for stipulating one resolution rather than another. But arbitrary stipulation on intrinsic grounds will always leave resolutional remainder. 
Second, resolutional remainder is a metaphysical, not a psychological phenomenon. ${ }^{6}$ Arbitrary stipulation in cases of vagueness settles the question of whether the predicate applies, while in hard cases, after arbitrary stipulation, the metaphysical question of how the items normatively relate remains open. Whether we feel angst, uncertainty, or unease about the matter is not at issue; after all, you might be a confident stipulator who is unfussed about the fact that your epistemic peers could have stipulated differently or that the case is high stakes. The issue concerns the metaphysical upshots of arbitrary stipulation in answer to the question of what relation holds - does arbitrary stipulation close the matter or not? In cases of vagueness, it does; in hard cases, it does not.

Could the fact that hard cases are normative be why arbitrary stipulation yields resolutional remainder? Perhaps it is the feature of being a normative hard comparison that makes arbitrary stipulation in such cases different from arbitrary stipulation in nonnormative cases of vagueness (Constantinescu 2012). The problem with this suggestion is twofold. For one thing, if arbitrary stipulation resolves vagueness in nonnormative hard cases but not in normative hard cases, an account is owed of why this should be. One way such an account could be developed is by exploring whether all normative hard cases are what Gallie (1956) calls "essentially contested," that is, by their nature always open to further substantive debate, while nonnormative ones are not. Perhaps the proponent of vagueness could develop an account along these lines. But note that in doing so she would be abandoning what we currently understand as vagueness and proposing that there is some new phenomenon according to which arbitrary resolution leaves resolutional remainder. I suggest a way to think about this new phenomenon in the last section of this chapter.

But there is a deeper worry. If the hardness of hard cases cannot be resolved by arbitrary stipulation according to the vagueness theorist, it might be wondered what work vagueness does in explaining such cases. After all, if attempts to resolve the putative vagueness in such hard cases must fail to provide an intrinsic resolution in such cases, why should we think that vagueness is what explains the case in the first place? An appeal to vagueness would be otiose in normative hard cases. Sharpening the question gets us nowhere; we are left where we began, namely, with a substantive, normative question about how two items normatively relate in a hard case.

None of this is to deny that vagueness holds in the normative domain or even in hard cases. ${ }^{7}$ Vagueness most plausibly holds when the items at stake are quite similar and we need arbitrarily to "draw a line" among these similar items to determine what counts as being V. Excrement, for example, smells disgusting. If we alter a steaming pile of it ever so slightly by adding one drop of Chanel No. 5, it will still smell disgusting. But if we add another drop and then another and another, at some point it will 


\section{Ruth Chang}

no longer smell disgusting. Exactly where we draw the line and call the smell no longer disgusting is an arbitrary matter because it is vague whether something smells disgusting. The same goes for determining whether a life is good. Fixing all the features that go into making a life good, it may be an arbitrary matter where we draw the line in calling such lives good enough to count as "good lives." The notion of a good life may well be vague. But the problem of comparing two qualitatively different lives with respect to "goodness as a life" in hard cases is not a matter of drawing a line among similar lives to determine which lives are good enough to count as "better as a life" than other lives. A property can be vague (e.g., "long") while its comparative is not (e.g., "longer than").

In sum. Vagueness can be resolved by arbitrary stipulation, but in hard cases, attempts to resolve the hardness by arbitrary stipulation leave resolutional remainder. Vagueness cannot accommodate resolutional remainder unless it is taken to be a phenomenon that is different from how it has so far been understood. If vagueness is understood in this new way, there is reason to think that, as an explanation of hard cases, vagueness thereby becomes otiose.

\section{The Problem of Normative Leakage}

Hard cases raise an interesting puzzle for rational choice (Chang 1997). Suppose, as many do, myself included, that a comparison between alternatives $\mathrm{A}$ and $\mathrm{B}$ with respect to $\mathrm{V}$ determines the rational choice between $\mathrm{A}$ and $\mathrm{B}$, where $\mathrm{V}$ is what matters in the choice between them. ${ }^{8}$ Suppose, moreover, that as the vagueness theorist would have it, in a hard case of comparison, it is always rational arbitrarily to stipulate that one is better than the other. Putting these suppositions together, we might accept the following "bridge principles" connecting comparisons with rational choice:

\section{Bridge Principles}

(1) If $\mathrm{A}$ is better than $\mathrm{B}$ with respect to $\mathrm{V}$, and $\mathrm{V}$ is what matters in the choice between them, then one should rationally choose $A$.

(2) If $\mathrm{A}$ is worse than $\mathrm{B}$ with respect to $\mathrm{V}$, and $\mathrm{V}$ is what matters in the choice between them, then one should rationally choose $B$.

(3) If $\mathrm{A}$ and $\mathrm{B}$ are equally good with respect to $\mathrm{V}$, and $\mathrm{V}$ is what matters in the choice between them, then it's always rationally permissible to flip a coin to determine which to choose.

(4) If the comparison between $A$ and $B$ with respect to $V$ is hard, and $\mathrm{V}$ is what matters in the choice between them, then the choice is hard, and it's always rationally permissible to arbitrarily stipulate that one is better than the other and choose that option. 
(Although both 3 and 4 involve arbitrariness along the route to choice, only the latter involves arbitrary stipulation that one alternative is better with respect to V.) Going forward, let us assume that these bridge principles hold.

Given these principles, hard cases permit what we might call "normative leakage"; they can lead to the loss of normativity for a chooser through a series of rational choices. ${ }^{9}$ Suppose you are contemplating whether to pursue investment banking or interior design and that the comparison of those careers, and thus the choice between them, is hard. Following bridge principle 4, you arbitrarily stipulate that interior design is better and rationally choose it. I now offer you the opportunity to consider a banking career instead, one that is identical to the one you forewent except worse in that there will be no year-end bonus. The comparison between the two careers is once again hard and so is the choice. Employing bridge principle 4, you arbitrarily stipulate that the banking career-sans-bonus is better than the design career and choose accordingly. But now you have ended up with a career - banking-sans-bonus - that is worse than a career you could have had a moment ago - banking through a series of rational choices involving hard cases. If arbitrary stipulation is always permissible in hard cases, then hard cases make us liable to normative leakage.

If we understand hard cases as cases of vagueness, can normative leakage be blocked? Since the vagueness theorist maintains that arbitrary stipulation is always permissible in the face of a hard case, it may seem that vagueness permits normative leakage. But the opposite is true. Vagueness theorists hold as an integral part of their theory "penumbral truths," such as those given by the ordering properties of the usual trichotomy of relations, like transitivity and consistency. This is precisely to block untoward consequences that would otherwise ensue, such as normative leakage. (Strictly speaking, some minority views, e.g., degree theorists, reject penumbral truths and have been uniformly criticized as inadequate accounts of vagueness on that score (e.g. Fine 1975)). Since all mainstream accounts of vagueness accept penumbral truths as key components of the account, I set minority views aside. ${ }^{10}$

Put supervaluationally, there can be no sharpening of "better than as a career" that permits the three judgments that interior design is better than banking, that banking is better than banking-sans-bonus, and that banking-sans-bonus is better than interior design. Each alternative meaning of "better than as a career," then, will obey consistency constraints and the transitivity of "better than." Thus there is no sharpening on which normative leakage will be permissible. Moreover, "switching" between sharpenings in cases of putative normative leakage would involve equivocation across choice situations. You might judge that design is better 1 than banking, that banking-sans-bonus is better 2 than design, and that banking is better 3 than banking-sans-bonus, but it would be odd to 


\section{Ruth Chang}

make choices across different possible careers on the basis of such equivocal judgments. Broome sums things up nicely on behalf of vagueness theorists: an agent who normatively leaks "necessarily does something wrong." (Broome, this volume: 46).

The fact that vagueness blocks normative leakage might be thought to count in its favor as an explanation of hard cases. After all, if hard cases should block normative leakage and understanding them in terms of vagueness allows them to do so, then vagueness meets that adequacy condition of an explanation of hard cases.

But should hard cases block normative leakage? I want to suggest that it is an intrinsic feature of hard cases that they make normative leakage in the hard choices they determine rationally permissible. If hard cases rationally permit normative leakage, then the problem of normative leakage is not the problem of explaining hard cases and the choices they underwrite in a way that blocks such leakage. On the contrary, the correct explanation of hard cases would show how such leakage in the context of rational choice is rationally permissible. Since vagueness prohibits normative leakage, it over-delivers as an explanation of hard cases, imposing on them a feature that is alien to them.

To see why the rational permissibility of normative leakage is an intrinsic feature of hard cases, we need to ask what role hard choices play in rational life. To tackle this question, we can start by imagining a world without hard cases - in particular, a world in which it never seems that one of the standard trichotomy of relations fails to hold between two items. In Easy World, it is always evident which of the standard trichotomy of relations holds, and what's more, we are always right. We can immediately, reliably, and veridically see that banking is better than interior design, living in the country is better than living in the city, marrying Adam is better than marrying Brian, and so on. Perhaps we have evolved to have unfailing normative instincts that give us direct access to normative facts so that all comparative normative truths hit us like basic perceptual truths we can discover by just looking. What would such a world be missing?

Easy World has two striking features. First, normativity would be a dictatorial overlord, always determining in every possible set of circumstances whether one thing is at least as good as another and, given our first three bridge principles, what you should think, feel, and do in that situation. In a world with only easy choices, there would always be a best career, place to live, person to marry, number of kids to have, car to buy, and so on since between any two options, one would be at least as $V$ as the other. Sometimes normativity would determine that two options are equal bests, in which case it wouldn't matter which you choose, and so you could rationally flip a coin between them. If all choices were easy, normativity would dictate every aspect of rational life, including when you should flip a coin between alternatives. 
Second, rational agency would be fundamentally passive. In a world with only easy choices, rational agency would be a passive capacity an instinct or a normative perception - to discover orders dictated by normativity concerning what to believe, feel, and do in any situation. To exercise rational agency, all you would need to do is sit back, relax, and let normative truths tell you how you ought rationally to respond. There would be no room in Easy World for active rational agency - that is, exercises of agency in which the rational agent herself determines for herself what she should rationally think, feel, and do.

Of course, there is a version of a world without hard choices in which we don't immediately perceive normative comparative truths but have to engage our rational capacities to discover those truths. This "Challenging World" may be thought to be our actual world: one thing is always at least as good as another, but it often requires exercises of rational agency to determine that this is so. Challenging World, however, is like Easy World in the respects of interest: although it takes rational effort to discover what normativity demands of us, normativity is nevertheless a dictatorial overlord, always telling us what is at least as good as what. And although discovering normative truths is hard work, involving the exercise of our rational capacities, those exercises are passive in the sense of interest: they permit us to discover existing truths, not give us the power to determine or create normative truths.

This thought experiment suggests that hard cases play two important and distinctive roles in our world. First, they give rise to junctures in human life in which normativity "runs out" or is "silent" as to what a rational agent should think, feel, or do. ${ }^{11}$ Second, because normativity does not determine a rational response in such cases, they make space for the exercise of active rational agency in which a rational agent can determine for herself what it would be rational for her to think, feel, and do.

This space for the exercise of active rational agency allows agents rationally to change their minds about what they should think, feel, and do and to do so at a normative cost. Faced with a hard case involving banking and interior design, you might rationally choose design. In the next moment, you might be faced with another hard case involving design and banking-sans-bonus. You might rationally choose bankingsans-bonus. This series of rational choices in hard cases leaks normativity; you end up choosing a career that is worse than one you could have had moments before. But this is what rational human life is like. There is nothing rationally to regret; leaking normativity in the course of human life is a feature of rational human life. Human rationality makes space for rational agents to change direction, switch gears, pursue a new path, try out something new, and so on, even though doing so entails leaking normativity over the course of their life. Hard choices are the junctures at which such leakage is rationally permissible. We might say that the freedom to leak normativity is what hard cases are for. 


\section{Ruth Chang}

The rational permissibility of normative leakage in hard cases is what allows rational agents to determine the direction of their lives. I believe that this self-determination involves the exercise of a robust normative power that lies at the heart of an understanding of rational agency as active (Chang 2021). Vagueness, which makes normative leakage a mistake, misunderstands the role of hard cases in human life.

A proponent of vagueness can of course appeal to extrinsic factors to explain how leakage in hard cases is rationally permissible. Those extrinsic factors may override the rational mistake inherent in normative leakage if hard cases are cases of vagueness. But if hard cases play the distinctive role in rationality that I have suggested, the rational permissibility of such leakage is intrinsic to them. ${ }^{12}$

In sum. Hard cases provide junctures in life in which agents can actively determine what they should think, feel, and do, despite the normative costs. They are cases in which normative leakage is rationally permissible. Vagueness, which makes normative leakage a rational mistake, is therefore inadequate as an explanation of such cases.

\section{Parity and Hard Cases}

Hard cases offer us a path to a new way of thinking about the structure of normativity. They give us reason to reexamine an unreflective assumption we make about normativity: when we make normative comparisons with respect to some $\mathrm{V}$, normativity permits only three possibilities: A is better than B, worse than it, or they are equally good with respect to $\mathrm{V}$. Normativity is assumed to be "trichotomous" in structure. This assumption can be seen to derive from an analogue in the nonnormative domain; when making nonnormative comparisons, say, with respect to length, the nonnormative domain permits only three possibilities: one item is longer, less long, or equally as long as the other. "Trichotomy," the view that between two comparable items with respect to some covering consideration, only one of three relations corresponding to or analogous to the trichotomy of relations "more than", "less than," and "equal to" could hold between them, has been assumed by theorists working in the normative and nonnormative domains alike. It is foundational to much work in the social sciences, especially economics and decision theory but is also widely assumed in the humanities and physical sciences.

I have argued elsewhere that Trichotomy does not hold in the normative domain. This is because the significant qualitative differences in normativity between items make Trichotomy too crude a view to capture the full range of possible normative relations among items (Chang 2016a). When we compare two careers with respect to goodness as a career, two policies with respect to justice, two reasons with respect to normative strength or significance, two sets of evidence with respect to warrant, or two scientific theories with respect to explanatory power, we 
cannot assume that these normative covering considerations - goodness as a career, justice, normative significance, warrant, explanatory power are like nonnormative covering considerations, such as length, weight, and volume, that permit only trichotomous rankings. There is a fourth, sui generis, master relation by which things can be normatively related, what I call "on a par." Two careers can be on a par with respect to goodness as a career: neither is better than the other but nor are they equally good. They are nevertheless comparable; they are qualitatively different and yet in the same neighborhood of goodness as a career, they are on a par. Similarly, statistical evidence that the defendant committed the tort may be neither stronger, less strong, nor equally as strong as forensic, individualized evidence arguing the contrary. It isn't that we can't compare the epistemic warrant of each kind of evidence; we're not trying to compare epistemic and practical reasons, for instance, or a weight and a volume. The statistical evidence is on a par with the individualized evidence. In short, when making normative comparisons, we should reject Trichotomy and accept instead Tetrachotomy, the view that between two comparable items with respect to some covering consideration, only one of four relations - "better than," "worse than," "equally good," and "on a par" - could hold between them.

Hard cases are, I suggest, cases in which the items are on a par. Normativity is tetrachotomous, not trichotomous, in structure. ${ }^{13}$ There are four, not three master relations in the normative domain.

There are of course many questions that arise in the face of such a seemingly radical proposal, many of which I try to tackle elsewhere, and I won't repeat my arguments here. My aim instead is to describe how parity solves the two problems we have raised for vagueness theorists.

The first, concerning resolutional remainder can be straightforwardly explained. On the assumption of Trichotomy, arbitrarily stipulating that, say, investment banking is better than interior design leaves resolutional remainder because Trichotomy is false: the careers are on a par. The question of what normative relation holds between the careers cannot be settled by arbitrarily stipulating that one is better if the normative truth is that they are on a par. Arbitrary stipulation leaves resolutional remainder in hard cases because we assume that Trichotomy holds.

The second problem is to explain how hard cases, understood as cases of parity, rationally permit normative leakage. To solve this problem, we must ask what bridge principle connects the fact that options are on a par with how rationally to choose between them. That is, we need a bridge principle that replaces principle 4 mooted earlier for hard cases. I have suggested that the bridge principle is disjunctive: if options are on a par, it is rationally permissible to commit to (a feature) of one, thereby creating normativity in its favor and perhaps now having most reason to choose it or to drift into one of the options - that is, intentionally choosing it on the basis of some consideration that counts in its favor. 


\section{Ruth Chang}

\section{Bridge Principle for Hard Cases}

4* If $\mathrm{A}$ and $\mathrm{B}$ are on a par with respect to $\mathrm{V}$, and $\mathrm{V}$ is what matters in the choice between them, then it is always rationally permissible to commit to (a feature of) one of them, thereby creating a reason to choose it, which may then give one most all-things-considered reasons to choose it, or to drift into one option - that is, to intentionally choose it on the basis of already-existing reasons but without committing to any of its features.

The difference between committing and drifting is of the greatest importance. When you commit to something and thereby create a reason to choose it, you are engaging in the volitional activity of putting yourself behind that consideration. It is this putting yourself behind something, say, the lucre you will earn as an investment banker, that creates normativity in favor of the banking career. Since creating reasons is an active exercise of rational agency, hard cases, understood in terms of parity, rationally permit you to determine for yourself what you have most reason to think, feel, and do. Normativity doesn't dictate what you should think, feel, and do in every possible circumstance; it leaves you with "hard choices" that is, cases in which the items are on a par, and you have the freedom to create for yourself a reason to pursue one thing over another, a freedom that is itself not governed by normativity. Committing to something is something rational agents $d o$ as an exercise of their rationality that is not guided by reasons (Chang 2021). In a hard choice, then, you can create a new "will-based" reason for yourself to pursue banking-sans-bonus, thereby making it better, we can suppose, than interior design. There is no mistake of rationality even though a moment ago you could have had banking with a year-end bonus. This is because hard choices allow you space to change direction in your life by creating normativity that favors new life paths even at the cost of leaking normativity. Moreover, how much normatively it is permissible to leak is constrained by the requirement that the options are in fact on a par. Rational life allows you to change direction at normative cost without making a rational mistake, but too much leakage - for example, leakage when options are not on a par - will undermine rational agency.

None of this is to say that hard cases, understood in terms of parity, must always permit normative leakage. If today you commit to the autonomy afforded by a career in interior design, your doing so confers normativity in favor of the design career that wasn't there before and which could now give you most all-things-considered reasons to become an interior designer over a banker. Tomorrow, when you are offered the chance to reconsider your choice of career, this time being offered the same banking career but without a year-end bonus, the design career may be better than both the original banking career and the banking 
career without the bonus because of your commitment. In this way, what you chose previously can constrain what you can rationally choose subsequently; commitment in one choice can block what would have been normative leakage in a subsequent choice (Chang 2005).

Understanding hard cases in terms of parity also provides us with a diagnosis of the hardness in hard cases. Hard cases are hard because we assume too crude a view of the structure of normativity - that all normatively significant qualitative differences can be forced to fit within the usual three categories of relation corresponding to "more," "less," and "equal" in the nonnormative domain. Once we allow for the possibility of parity, determining which relation holds between two items in a hard case will be (relatively) easy: the items are on a par. But there is a hardness that remains in hard choices. In hard choices, we are rationally permitted to commit or to drift, and which we do is not a choice guided by reasons but a volitional activity. The hardness is volitional: can we commit or is the will content to drift? Committing to something is hard; it is a matter of putting your very self behind something. We commit in our friendships, love relationships, and personal projects. But commitment beyond these spheres is not yet recognized as part of what it is to be a rational agent. Instead, we are taught that when we face a hard choice one option is at least as V as the other and that our job as rational agents is to discover which it is. We are taught that rationality is a matter of discovery of reasons, not their creation through our commitments.

In sum. If we understand hard cases as cases of parity and not vagueness, we can explain both why arbitrary resolution of hard cases leaves resolutional remainder and why normative leakage is rationally permissible. Hard cases and the hard choices they underwrite are junctures in human life in which rational agents can change direction in their lives despite the normative costs of doing so.

I end with a nudge for vagueness theorists - at least of the traditional, non-epistemicist variety. Although I believe that indeterminacy understood as vagueness is the least plausible of the "i" explanations of what I have called "paradigmatic" hard cases, I also believe that those who appeal to vagueness to explain such cases are very close to the truth of these cases, i.e., that they are almost partisans of parity. This is because, they share with defenders of parity two key insights about hard cases namely, (i) that they are not cases of incomparability and (ii) that it is implausible to think that in all hard cases between qualitatively different items, one is always at least as good as the other but we just don't know which. Surely, we can compare two careers, places to live, and human lives, even if they are qualitatively different. And is it really plausible to think that between every pair of qualitatively different careers, such as banking and interior design, there is always a precise truth about whether 


\section{Ruth Chang}

increasing the salary of one by a dollar thereby makes it better, but we are too stupid to discover that truth? Maybe such precision holds of baldness and being a heap, but it is hard to believe it holds of goodness as a career, well-being, justice, epistemic warrant, and the like.

I wonder whether proponents of vagueness have come to vagueness as an explanation of hard cases largely by default. Indeed, indeterminacy sometimes seems to serve as a dumping ground for unclear or difficult normative determinations. Once the vagueness theorist accepts that not all hard cases can be explained by incomparability or ignorance, then on the assumption of Trichotomy, indeterminacy is the only remaining explanation. As I have argued in this paper, however, indeterminacy understood as vagueness is not the right kind of phenomenon to explain hard cases.

To get on the path to parity, the vagueness theorist needs only to take two steps. First, she needs to recognize that the assumption of Trichotomy is unreflectively built into certain, especially economic, approaches to hard cases and that this assumption requires examination and defense. Second, she needs to investigate the nature of the normative considerations she is attempting to model, without simply assuming that they are amenable to the same modeling fit for nonnormative considerations, such as length, weight, and volume. I have argued that qualitative differences in normativity make space for a fourth, sui generis way in which items can be normatively related (Chang 2002a, 2013a, 2013b, 2016a). The structure of normativity is not like the structure of nonnormativity. We need parity to explain hard cases.

The history of philosophy is filled with attempts to explain difficult phenomena in familiar terms. When familiar tools strain to explain very real and important phenomena, we make philosophical progress by adding new tools to our explanatory toolbox. Hard cases call on us to reexamine deep and unreflective assumptions we make about the structure of normativity. By adding parity to our explanatory toolbox, I believe that we put ourselves on a path to a deeper understanding of hard cases and the nature of normativity.

\section{Notes}

1 Thanks to the editors of this volume and to the audience at the UK ALPP conference, especially Matt Kramer, Rae Langton, and Re'em Segev, for comments that led me to make some useful clarifications, and to Kit Fine for discussion about the varieties of vagueness that saved me from many infelicities and helped me to simplify my arguments.

2 If my arguments are correct, the positive arguments offered by proponents of vagueness are not. The most trenchant of these arguments are provided by John Broome (1997, this volume). If Broome's arguments are correct, then two ways of understanding value relations that make room for both vagueness and the determinate failure of the usual trichotomy of relations offered 
by Wlodek Rabinowicz (2007, 2012, see also 2009) and myself (2002b, 2016a) are mistaken.

I believe that Broome's arguments depend on a controversial assumption. They assume that all banking careers (or what not featuring in vagueness) can be arrayed on a spectrum such that it makes sense to say of each career on the spectrum that it is (trichotomously) "closer" or "further" from being a version of the banking career that is definitely better (or worse) than the interior design career. I have suggested (Chang 2002a) that there are at least two reasons we cannot expect that an item like a career can always be tweaked with small, successive normative changes to generate a spectrum of such careers where each career is increasingly good as a career. First, a small normative change can trigger a new aspect of goodness of career that wasn't relevant before, thus making the new career not better with respect to goodness as a career but only with respect to some additionally smuggled in covering consideration. I call this the Hegelian Proviso. Second, a small normative change in a career can make a career not better but worse than it was before because of organic unities. I call this the Aristotelian Proviso. These provisos show that we cannot assume that a spectrum of the sort on which Broome's arguments rely is always available. (Although I rely on a similar spectrum in my arguments for parity, my burden is to show that there is at least one such spectrum involved in a hard case, not that all hard cases are amenable to treatment in terms of the kind of spectrum that Broome envisages).

Other proponents of vagueness have offered mostly negative arguments against my arguments that hard cases are not cases of vagueness. Some telegraphic worries about such arguments that could not be addressed explicitly in this chapter are as follows:

Wasserman's (2004) objections suggest (a) that there is a difference in phenomenology involving vagueness of monadic as opposed to polyadic predicates, but I can see no difference in phenomenology in the relevant cases; my point is that in hard cases, it seems determinately that none of the usual trichotomy of relations holds (that the one career is not better than the other) and we are not inclined to judge that it's unclear whether 'better than' holds, as we might in cases of vagueness so the phenomenology is different; (b) maintains that the idea of resolutional remainder begs the question against a previous argument that ignorance as to which of the usual trichotomy holds is not always in play in hard cases since the idea of a resolutional remainder presupposes that one of the usual trichotomy of relations holds but we don't know which. This worry itself, it seems to me, begs the question against the possibility of parity and misunderstands the idea of resolutional remainder, which does not entail the claim that one of the usual trichotomy holds even after arbitrary stipulation but that the substantive question of what relation holds between items remains open.

Klocksiem (2010) rightly points out that the Small Improvement Argument alone does not establish incomparability but is consistent with vagueness, which is why there is a need to argue explicitly against the possibility that one or both of the Small Improvement Argument and the Chaining Argument trade on vagueness, which I try to do in Chang 2002a.

Sugden (2009) rightly argues that if we assume trichotomy and frame the question about hard cases as one about modelling them by the relation "at least as R as," then we might as well think about them as cases of vagueness since he fiats no space for contemplating a normative reality that defies these assumptions. However, the philosophically interesting question is about normative reality of hard cases, not how we can impose neat decision-theoretic 
models on them that may not accurately reflect their features (see also Qizilbash 2014).

Elson's (2014) interesting and complex argument that my arguments for parity trade on vagueness wholly depends on the thought that "is comparable" (or being comparable) (with respect to $\mathrm{V}$ ) can be vague without any one of "better than," "worse than," or "equally good" (with respect to V) being vague, assuming trichotomy. I don't see how this is plausible though it is a logical possibility. As a tetrachotomist, I would deny that "is comparable" (with respect to V) can be vague without at least one of "better than," "worse than," "equally good," or "on a par" (with respect to V) being vague (where the vagueness of course could derive wholly or partly from V-ness). If comparability is constituted by a certain range of relations, its vagueness seems to be a function of the vagueness of one of its components. Moreover, in Elson's (2017) it is suggested that the fact that there can be a quandary over how to trade off multiple different components of the covering value makes for a prima facie case in favour of vagueness, thereby shifting the burden to opponents of vagueness to explain why vagueness does not explain these cases. But a quandary over the "rate of trade-off" across components of, say, justice, is the bread and butter of substantive normative theorizing; it is this quandary, which is substantive, that accounts for many of the competing "conceptions" of justice that are each substantive and not simply sharpenings of the vague term or property of being just. Simply having the form of there being multiple legitimate ways to relate different criteria is not ipso facto grounds, it seems to me, for accepting vagueness as the default explanation of hard cases.

Andersson (2015) suggests that my assumption that a small unidimensional difference in an item cannot trigger incomparability where before there was comparability already begs the question of whether the items are comparable because "all differences [can] be understood to be composed of small uni-dimensional differences" (p. 252). However, this principle, which I understand normatively, not nonnormatively as Andersson supposes in his main text (p. 673 though he claims the arguments apply even to a normative version of the principle), does not beg the question since there are normative differences between incomparable items, too, which presumably can be broken down into small unidimensional differences if normative differences can. As Andersson himself notes, I say very explicitly that the intuition that a small normative change in one dimension of the covering consideration in one item is not sufficient to trigger incomparability with some other item if before those items were comparable holds in a demarcated set of cases and not universally, and I lay out two kinds of cases in which it does not hold. So the question is whether my appeal to the principle holds in the cases I have in mind. Here, all I can do is urge the reader to think of such cases for her or himself - laying out any single case in all the necessary detail would be not only too onerous but ultimately controversial for at least some readers. I suggest that the Mozart and Michelangelo case is such an example.

3 The dialectical point of focusing on paradigmatic hard cases is to exclude cases involving two nearly identical items about which the "hardness" in comparison, if indeed there is hardness, may not be of the same sort as the hardness involved in hard cases involving two qualitatively different items. (In other work, I refer to this amorphous class as "superhard.") Throughout this chapter, I assume that ignorance (as opposed to epistemic vagueness) is not the problem, though exactly how to distinguish ordinary ignorance from the ignorance that is putatively vagueness is a difficult question. (Again, in previous work, I explore arguments against the idea that in hard cases "at 
least as good as" holds between items, but we just don't know which in the above (Chang 2002a).) I also assume that incommensurability, the idea that items cannot be measured on the same cardinal scale representing the covering consideration, is a nonstarter since the hard cases of interest do not require commensurability for comparability.

4 We could hold instead that the vagueness is not in which of the usual trichotomy of relations holds but in whether the options are comparable/incomparable. For this indeterminacy to hold, however, there must be indeterminacy in what relation holds, or so I will suppose.

5 Extrinsic factors are, of course, always available to resolve vagueness in nonarbitrary ways. Tom Dougherty (2016) suggests that social conventions can step in to solve indeterminacies in morality. It may be worth noting that views of vagueness that appeal to extrinsic features to ground nonarbitrary resolution of vagueness need special arguments to explain why arbitrary resolution would not be permitted if, for example, the sharpenings are split 50-50 or the degree of truth of each proposition is the same.

6 I suspect I am to blame for some of my interlocutors treating resolutional remainder as a psychological phenomenon. In Chang 2002a, I try to elucidate the metaphysical idea that the question of what relation holds remaining open by talking of the "perplexity" over what relation holds "persisting." Here I meant "perplexity" as a conundrum, difficulty, puzzle, not a psychological state of being puzzled or perplexed.

7 Indeed, the presence of vagueness and some of the other " $i$ " phenomena may help to obscure what is really explains hard cases. We are, to be sure, ignorant in hard cases, but it is a mistake, I have argued, to think that ignorance explains why the case is hard.

8 In Chang 2016b, I argue for a strong and tight connection between comparisons and rational choice: that if we (i) work with master comparative relations, R ("better than," "worse than," "equally good," and "on a par" (to be explained in the text that follows)); (ii) make the relata, A and B, include anything that can be said to be an object of choice; and (iii) allow covering considerations, $\mathrm{V}$, to be whatever might matter in a choice between items, comparative facts of the form "A R B with respect to V" provide the grounds of all rational choice: they are that in virtue of which a choice is rational. According to "comparativism," comparisons occupy center stage in understanding practical normativity, whether you are a consequentialist, deontologist, virtue theorist, perfectionist, etc., because they are that in virtue of which choices, intentions, and actions are rational or normatively justified. Moreover, they provide a unified framework within which we can conduct debates within both practical and theoretical normativity - comparative facts provide the ground not only of rational choice but also rational belief.

9 The idea of normative leakage is a cousin to the familiar idea in decision theory that cyclical preferences are disallowed on the pragmatic grounds that they would allow agents to money pump. We might say that cyclical comparisons in conjunction with bridge principles lead to the possibility of "normativity pumping."

10 In any case, even degree theorists are subject to the argument from resolutional remainder; insofar as degrees can be equal, arbitrary stipulation resolves the case but it does not do so in hard cases without resolutional remainder.

11 As we will suggest in the next section, normativity "runs out" only on the assumption that "better than," "worse than," and "equally good" are the only master relations. 
12 Broome (this volume) cleverly notes that, given certain (controversial) assumptions, vagueness theorists can account for regret over a past choice by "distributing" the rational error involved in normative leakage. If you change your mind in the careers case, the rational mistake can be put mostly on your initial choice to go for interior design. But even if the rational error in normative leakage can be "distributed" in the way that Broome suggests, normative leakage always involves making a rational mistake somewhere in one's choices. Hard choices allow normative leakage without there being any rational error. (The controversial assumptions of Broome's argument are, first, that all banking careers can be arrayed along a spectrum of trichotomously increasing goodness as a career so that at some point along the spectrum, there is a banking career that is definitely better than the interior design career and, second, that there are trichotomous degrees of rational permissibility in choosing a career that are isomorphic with this spectrum of trichotomously increasing degrees of goodness as a career).

13 I have implied that trichotomy holds in the nonnormative domain and that tetrachotomy holds in the nonnormative domain. But this is not quite right. There is some reason to think that both domains are structured tetrachotomously - that is, that within each domain, there are properties or covering considerations that permit of tetrachotomous orderings. Within the normative domain, for instance, some normative covering considerations, such as "goodness of number of lives saved," where the goodness is measured by the number of lives saved, have a trichotomous structure - saving five lives must be better, worse, or equal to saving one life since their normative relation is determined by how many lives are saved and numbers can only be greater, lesser, or equal to another. Similarly, some nonnormative covering considerations may admit of tetrachotomous ordering. Which is more bulky, a bicycle or a $2 \times 4$ wall stud? Bulkiness is a multi-component covering consideration with qualitative aspects that arguably need not relate items trichotomously. Similarly, we might wonder whether an orangey-red patch must be redder, less red or equally as red as a purply-red patch. A bicycle and piece of lumber may be on a par in bulkiness, and two qualitatively different-looking red patches may be on a par in redness. These are controversial claims that I leave aside here (but see Chang 2002b).

\section{References}

Akiba, Ken. (2004), 'Vagueness in the World' Nous 38/3: 407-429.

Andersson, Henrik. (2015), 'Parity and Comparability-a Concern Regarding Chang's Chaining Argument', Ethical Theory and Moral Practice 19/1: 245-253.

Barnes, Elizabeth. (2010), 'Ontic Vagueness: A Guide for the Perplexed', Nous 44/4: 601-627.

Broome, John. (1997), 'Is Incommensurability Vagueness?' In R. Chang (ed.), Incommensurability, Incomparability, and Practical Reason (Cambridge, MA: Harvard University Press), 67-89.

Broome, John. (2021), 'Incommensurateness is Vagueness', in H. Andersson and A. Herlitz (eds.), Value Incommensurability: Ethics, Risk, and DecisionMaking (Routledge).

Chang, Ruth. (1997) 'Introduction'. In Chang (ed.), Incommensurability, Incomparability, and Practical Reason (Cambridge, MA: Harvard University Press), 1-34. 
Chang, Ruth. (2002a), 'The Possibility of Parity’ Ethics 112:659-688.

Chang, Ruth. (2002b), Making Comparisons Count, (London: Routledge).

Chang, Ruth. (2005), 'Parity, Interval Value, and Choice', Ethics, 114: 331-350.

Chang, Ruth. (2012), 'Are Hard Choices Cases of Incomparability?' in Philosophical Issues, 22/1: 106-126.

Chang, Ruth. (2013a), 'Grounding Practical Normativity: Going Hybrid,' in Philosophical Studies, 164/1: 163-187.

Chang, Ruth. (2013b), 'Commitments, Reasons, and the Will,' in Shafer-Landau (ed.), Oxford Studies in Metaethics, 8: 74-113.

Chang, Ruth. (2016a), 'Parity: An Intuitive Case', Ratio 29/4:395-411.

Chang, Ruth. (2016b), 'Comparativism: The Grounds of Rational Choice'. In Weighing Values, edited by Errol Lord and Barry Maguire (New York: Oxford University Press).

Chang, Ruth. (2017), 'Hard Choices', Journal of the American Philosophical Association, 92: 586-620.

Chang, Ruth. (2021), 'What Is It to Be a Rational Agent?' in Ruth Chang and Kurt Sylvan (eds.), The Routledge Companion to Practical Reason (New York: Routledge), 95-110.

Chang, Ruth. (forthcoming), 'How to Avoid the Repugnant Conclusion', In Jeff McMahan, Tim Campbell, James Goodrich, and Ketan Ramakrishnan (eds.), Ethics and Existence: The Legacy of Derek Parfit (Oxford: Oxford University Press).

Constantinescu, Cristian. (2012), 'Value Incomparability and Indeterminacy' Ethical Theory and Moral Practice 15/1: 57-70.

Constantinescu, Cristian. (2016), 'Vague Comparisons', Ratio 29/4: 357-377.

Dougherty, Tom. (2016), 'Moral Indeterminacy, Normative Powers and Convention' Ratio 29/4: 448-465.

Elson, Luke. (2014), 'Heaps and Chains: Is the Chaining Argument for Parity a Sorites?' Ethics 124/3: 557-571.

Elson, Luke. (2017), 'Incommensurability as Vagueness: A Burden Shifting Argument', Theoria 83: 341-363.

Fine, Kit. (1975), 'Vagueness, Truth, and Logic', Synthese 30: 265-300.

Gallie, W.B. (1956), 'Essentially Contested Concepts', Proceedings of the Aristotelian Society 56: 167-198.

Griffin, James. (1986), Well-Being (Oxford: Oxford University Press).

Klocksiem, Justin. (2010), 'In Defence of the Trichotomy Thesis'. Acta Analytica 25/3: 317-327.

Qizilbash, Mozzafar. (2005), 'Transitivity and Vagueness', Economics and Philosophy 21:109-131.

Qizilbash, Mozzafar. (2007), 'The Mere Addition Paradox, Parity, and Vagueness', Philosophy and Phenomenological Research 75/1: 129-151.

Qizilbash, Mozzafar. (2014), “Incommensurability" and Vagueness: Is the Vagueness View Defensible?’ Ethical Theory and Moral Practice 17/1:41-54.

Rabinowicz, Wlodek. (2007), 'Value Relations' Theoria 74/1: 18-49.

Rabinowicz, Wlodek. (2009), 'Incommensurability and Vagueness', Aristotelian Society Supplementary Volume 83: 71-94.

Rabinowicz, Wlodek. (2012), 'Value Relations Revisited', Economics and Philosophy 28/2:133-153.

Sainsbury, Mark. (2010), 'Why the World Cannot be Vague', The Southern Journal of Philosophy 33/1: 63-81. 


\section{Ruth Chang}

Schoenfield, Miriam. (2015), 'Moral Vagueness Is Ontic Vagueness', Ethics $126,2,257-282$.

Sugden, Robert. (2009), 'On Modelling Vagueness - and on Not Modelling Incommensurability' Aristotelian Society Supplementary Volume 83: 96-113.

Thomas, Teru. (forthcoming), 'On Evaluative Imprecision', in Jeff McMahan, Tim Campbell, James Goodrich, and Ketan Ramakrishnan (eds.), Ethics and Existence: The Legacy of Derek Parfit (Oxford: Oxford University Press).

Wasserman, Ryan. (2004), 'Indeterminacy, Ignorance and the Possibility of Parity', Philosophical Perspectives, 18/1: 391-403.

Williams, J. Robert. (2008), 'Ontic Vagueness and Metaphysical Indeterminacy', Philosophy Compass 3/4: 763-788.

Williams, J. Robert. (2014), 'Decision Making Under Indeterminacy' Philosopher's Imprint 14: 1-34.

Williams, J. Robert. (2016), 'Indeterminacy, Angst and Conflicting Values' Ratio 29: 412-433. 